\title{
CAPACIDADE ANTIOXIDANTE DE HIDROLISADO ENZIMÁTICO DE FARELO DE GIRASSOL
}

\author{
Thaiza Serrano Pinheiro de Souza ${ }^{1}$; Ticiane Carvalho Farias ${ }^{1}$; Joel Pimentel de Abreu ${ }^{1}$; \\ Anderson Junger Teodoro ${ }^{1,2}$; Maria Gabriela Bello Koblitz ${ }^{1,2}$ (thaizasps@ gmail.com) \\ ${ }^{1}$ Programa de Pós Graduação em Alimentos e Nutrição (PPGAN) - Universidade Federal Estadual do Rio de \\ Janeiro (UNIRIO) \\ ${ }^{2}$ Escola de Nutrição - Universidade Federal Estadual do Rio de Janeiro (UNIRIO)
}

O girassol (Helianthus annuus L.) é uma planta oleaginosa e um dos subprodutos do processo de extração de óleo é o farelo de girassol, que contém um elevado teor de proteínas, fibras e compostos fenólicos. A capacidade antioxidante em alimentos à base de plantas pode ser atribuída a peptídeos antioxidantes que podem estar presentes naturalmente no alimento ou de forma encriptada na estrutura das proteínas. Com a hidrólise enzimática, peptídeos que se encontram encriptados são liberados, apresentando-se então em sua forma ativa. O objetivo deste trabalho foi testar a capacidade antioxidante do farelo de girassol (resíduo da indústria de óleo de girassol) a partir de hidrólise enzimática com diferentes proteases (alcalase e papaína). O farelo de girassol utilizado neste trabalho foi cedido pela Empresa Caramuru, e foi enviado seco e desengordurado e então foi moído. Foram realizados 2 diferentes testes para a obtenção das proteínas hidrolisadas a partir das enzimas alcalase e papaína e para cada amostra foi feito um branco, onde houve o procedimento de hidrólise sem a presença da enzima, segundo a metodologia proposta por Contreras et al. (2011). Foram realizados 2 ensaios de atividade antioxidante DPPH e ABTS, segundo Rufino et al. (2007) e foi determinado o teor de proteínas solúveis em TCA 0,22 M, segundo Castro \& Sato (2014). Todos os testes foram realizados em triplicata. Para as análises estatísticas foi utilizada a One-way ANOVA seguida do teste de Tukey ao nível de 5\% de significância. Com o teste ABTS, pode-se observar os seguintes resultados: $155,05 \pm 12,54 \mu \mathrm{mol}$ de trolox/g com a alcalase, e 234,45 $\pm 51,20 \mu \mathrm{mol}$ de trolox/g com a papaína e seus brancos 113,77 $\pm 51,20$ e 85,78 $\pm 14,92 \mu \mathrm{mol}$ de trolox/g respectivamente. Quanto ao teste com DPPH, os resultados encontrados formam: 125,05 $\pm 23,99 \mu \mathrm{mol}$ de trolox/g com a alcalase, e 220,45 $\pm 12,66 \mu \mathrm{mol}$ de trolox/g com a papaína e seus brancos 108,70 $\pm 8,11$ e 117,25 $\pm 11,09 \mu \mathrm{mol}$ de trolox/g respectivamente. Desta forma a papaína demonstrou capacidade de gerar maior atividade antioxidante no hidrolisado de farelo de girassol. A papaína proporcionou menor rendimento em proteínas solúveis em TCA $(68,59 \%)$, em comparação com a alcalase $(93,24 \%)$. Este resultado demonstra que a papaína promove menor grau de hidrólise, fazendo com que os peptídeos resultantes sejam de tamanho intermediário e estes, por sua vez, apresentem maior atividade do que peptídeos de tamanho pequeno ou proteínas intactas.

Palavras-chave: Helianthus annuus L.; proteases; antioxidante. 